\title{
Representações Sociais sobre Feminismo em Brasileiros/as
}

\author{
Naiana Dapieve Patias* \\ Universidade Federal de Santa Maria - UFSM, Santa Maria, RS, Brasil \\ ORCID: https://orcid.org/0000-0001-9285-9602 \\ Tayná da Silva Ferreira** \\ Faculdade Meridional - IMED, Passo Fundo, RS, Brasil \\ ORCID: https://orcid.org/0000-0001-6546-0786 \\ Icaro Bonamigo Gaspodini**** \\ Universidade do Vale do Rio dos Sinos - Unisinos, São Leopoldo, RS, Brasil \\ ORCID: https://orcid.org/0000-0003-4177-4734 \\ Paula Andréa Prata-Ferreira**** \\ Universidade Estácio de Sá - Unesa, Rio de Janeiro, RJ, Brasil \\ ORCID: https://orcid.org/0000-0002-1526-491X \\ Clarissa Pinto Pizarro de Freitas***** \\ Pontifícia Universidade Católica do Rio de Janeiro - PUC-Rio, Rio de Janeiro, RJ, Brasil \\ ORCID: https://orcid.org/0000-0002-2274-8728
}

\section{RESUMO}

O que se pensa e o que se fala sobre o feminismo é relevante para compreender os fatores que influenciam em sua adesão por parte da sociedade. Este estudo teve o intuito de investigar as representações sociais de feminismo em brasileiros/as e variáveis associadas. Participaram do estudo 731 brasileiros/as com idades de 18 a 79 anos, a maior parte do gênero feminino (78\%). Por meio de um questionário online, foi apresentada uma ficha de dados sociodemográficos e duas vinhetas: Vinheta Um (mãe, feminista e negra) e Vinheta Dois (universitária, antifeminista e branca). A análise de dados deu-se por meio de estatística descritiva e comparação entre grupos pelo teste U de Mann-Whitney e Kruskal-Wallis. A amostra total indicou que pessoas mais velhas, com filhos e com alguma religião atribuíram características mais positivas à Vinheta Dois. A amostra do gênero feminino atribuiu características mais positivas a Vinheta Um. Variáveis como a escolaridade, renda e áreas de conhecimento não apresentaram diferenças estatisticamente significativas no que diz respeito à atribuição de características às vinhetas.

Palavras-chave: psicologia social, feminismo, psicologia, representação social.

\section{Social Representations about Feminism in Brazilians}

\begin{abstract}
What people think and say about feminism is relevant to understand what factors may influence society to support the movement. This study aimed to investigate the social representations of feminism in Brazilians and associated variables. This study was conducted with 731 Brazilians, ranging from 18 to 79 years old, mostly women (78\%). Using an online
\end{abstract}


survey, we presented a sociodemographic questionnaire and two vignettes: Vignette One (mother, feminist, and black) and Vignette Two (undergraduate, anti-feminist, and white). Data analysis was performed using descriptive statistics and comparison between groups by the Mann-Whitney and Kruskal-Wallis U test. The sample indicated that older participants, with children, and with some religion attributed more positive characteristics to Vignette Two. The sample of women attributed more positive characteristics to Vignette One. Variables such as level of education, income, and areas of knowledge did not present statically significant differences regarding attributing characteristics to both vignettes.

Keywords: social psychology, feminism, psychology, social representation.

\section{Representaciones Sociales sobre Feminismo en Brasileños/as}

\section{RESUMEN}

Lo que se piensa y se dice sobre el feminismo es relevante para comprender los factores que influyen en su adhesión por parte de la sociedad. Este estudio tuvo como objetivo investigar las representaciones sociales del feminismo en brasileños/as y las variables asociadas. Participaron 731 brasileños de 18 a 79 años, la mayoría mujeres (78\%). A través de una encuesta en línea, se presentaron un cuestionario de datos sociodemográficos y dos viñetas: Viñeta Uno (madre, feminista y negra) y Viñeta Dos (universitaria, antifeminista y blanca). El análisis de datos se realizó mediante estadística descriptiva y comparación entre grupos mediante la prueba U de Mann-Whitney y Kruskal-Wallis. La muestra total indicó que las personas mayores, con niños y con alguna religión atribuyeron características más positivas a la Viñeta Dos. La muestra femenina atribuyó características más positivas a la Viñeta Uno. Las variables como la educación, los ingresos y las áreas de conocimiento no presentaron diferencias estadísticamente significativas con respecto a la atribución de características a las viñetas.

Palabras clave: feminismo, psicología, representación social, psicología social.

Para as mulheres, durante séculos, atribuiu-se o papel obrigatório da maternidade (Scott, 1986) e um lugar historicamente construído como inferior ao dos homens (Beauvoir, 1967). Embora o movimento social emancipatório de mulheres seja popularmente referido no singular como "feminismo", deve-se levar em conta uma pluralidade de influências teóricas e metodológicas responsáveis por diferentes correntes de "feminismos" (Esmeraldo, 2006).

Uma primeira onda pode ser identificada no início do século XIX, nos Estados Unidos e na Europa, como uma tomada de consciência das mulheres quanto às relações de dominação e exploração sustentadas pelo patriarcado (Pinto, 2010). Nesse momento, as principais pautas envolviam o direito à educação, ao trabalho, ao voto e ao divórcio. No Brasil, a bióloga 
Bertha Lutz destacou-se na liderança do movimento também conhecido como "sufragismo". A segunda onda representa novas reivindicações relacionadas à Revolução Industrial. Nesse momento, Simone de Beauvoir se torna um ícone revolucionário a partir da publicação de "O Segundo Sexo", em 1949. Beauvoir denuncia uma construção de significados culturais que posiciona a mulher ou o sexo feminino como subalterno e convoca a crítica aos aprendizados culturais de uma condição inferior (Beauvoir, 1967). Por fim, no início da década de 1990, diversas autoras passam a criticar uma noção universal de feminino, centrada nas reivindicações de mulheres brancas, heterossexuais e de classe média, dando início ao que se conhece como terceira onda do feminismo, de onde partem diversas correntes vigentes até então (Butler, 1990; Snyder, 2008; Scott, 1986). Exemplos dessas correntes são o feminismo liberal (Hartmann, 2017), o feminismo socialista ou feminismo marxista (Tong, 2018), o feminismo radical (Böhmer, 1993), o feminismo lésbico (Rich, 1980), o feminismo negro (Simien, 2004), o feminismo interseccional (Crenshaw, 1991) e o transfeminismo (Jesus, 2014).

Ainda que o feminismo busque liberdade e direitos para as mulheres, é visto por muitos como algo negativo. Uma pesquisa realizada nos Estados Unidos apontou que a representação social de feminismo entre as mulheres é hostilizada por questões culturais que as empregam com comportamentos não aceitáveis socialmente (Swirsky \& Angelone, 2014). Muitas acabam não se identificando com o feminismo, embora, durante as entrevistas, algumas indicaram que compactuam com os objetivos das lutas feministas. Isso faz pensar que representações sociais sobre o movimento podem tê-las impedido de aderirem ao movimento.

Representações sociais são significados, sentidos e explicações que se originam e se transformam no cotidiano, cuja função primordial seria tornar familiar aquilo que não é familiar, ou seja, fazer com que a própria não familiaridade se torne familiar (Moscovici, 2007). O conceito de representações sociais pretende fornecer outras dimensões a "conceitos anteriores, como opinião pública, atitude, representação coletiva, mito, estereótipo, cognição social, teoria dos esquemas, teoria da atribuição e mesmo de ideologia" (Guareschi \& Jovchelovitch, 2002, p. 193). Representações sociais são geradas por dois processos: a) ancoragem, que é basicamente associar o novo ao pré-existente, nomeando o que se está conhecendo no momento a partir do que já foi nomeado - rotulação, descrição, classificação; b) objetivação, quando aquilo que era abstrato se materializa e pode ser controlado (Moscovici, 2007). 
As pessoas partem do conhecimento popular, baseadas em sua cultura, por ser este mais acessível e se propagar com mais facilidade em relação ao conhecimento empírico que exige busca científica sobre o assunto (Alves-Mazzotti, 1994; Moscovici, 2007). O entendimento das representações sociais corrobora para intervenções baseadas em sua compreensão, na medida em que busca captar o pensamento social, do senso comum, do saber cotidiano (Arruda, 2002). Dessa forma, seu estudo pode contribuir para que preconceitos possam ser rompidos, proporcionando o saber real sobre o determinado assunto ou fenômeno do conhecimento (Diorio, Costa, \& Santana, 2017). No entanto, se organizarmos representações sociais em descrições imediatas ou diretas, reduzindo-as a estruturas e processos cognitivos, não será possível abranger sua processualidade (González Rey, 2008). Representações sociais podem ser definidas como produções da subjetividade social, capazes "de integrar sentidos e configurações subjetivas que se desenvolvem dentro da multiplicidade de discursos, consequências e efeitos colaterais de uma ordem social com diferentes níveis simultâneos de organização e com processos em desenvolvimento" (González Rey, 2008, p. 235, tradução nossa).

Assim como a Teoria das Representações Sociais busca o conhecimento compartilhado e destina-se a investigar temas/conceitos nem sempre valorizados pela ciência como, por exemplo, o movimento emancipatório de mulheres, as teorias de gênero também o fazem (Arruda, 2002; Meyer, 2004). É nesse sentido que as relações se estabelecem entre o gênero: papéis sociais compartilhados que, por muito tempo, guiaram ações indiscutíveis sobre quais comportamentos eram específicos para cada sexo biológico (Colling, 2017; Prehn \& Hüning, 2017). Segundo Meyer (2004), a noção de papéis de gênero é concebida no âmbito cultural, o qual se configura como um "campo de luta e contestação em que se produzem sentidos múltiplos e nem sempre convergentes de masculinidade e de feminilidade, noções essencialistas, universais e trans-históricas de homem e mulher - no singular" (p. 15). Tratase de um aprendizado realizado por meio de pedagogias culturais que acontece antes mesmo da criança nascer (Louro, 1999). Assim, as representações sociais sobre feminismo podem indicar possibilidades de intervenções no âmbito das ciências humanas e da saúde.

A psicologia entende que os processos que levam à formação das desigualdades de gênero derivam de processos externos relacionados ao ambiente cultural e interno, partindo da formação da subjetividade do sujeito diante do que lhe é apresentado e como é feita a internalização do conhecimento. Assim sendo, a desconstrução de preconceitos e discriminações exige processos tanto sociais, que promovam a conquista de espaço e direito para fomentar as discussões feministas, quanto pessoais, em sua subjetividade, para obter a 
internalização de novos conceitos que levem à liberdade e aceitação (Prehn \& Hüning, 2017; Scott, 1986). Desta forma, este estudo teve o intuito de investigar as representações sociais de feminismo em brasileiros/as e variáveis associadas. Neste estudo, não foi dado destaque a nenhuma teoria feminista específica, mas aos feminismos, de maneira geral, pois nem sempre há conhecimento, no senso comum, das diferentes perspectivas feministas.

\section{Método}

\section{Participantes}

A amostra foi composta por 731 brasileiros/as, entre 18 e 79 anos, sendo $78 \%$ mulheres $(M=30,83 ; D P=11)$. A maioria dos/as adultos/as eram solteiros/as (59\%), seguido de casados/as (25\%), união estável (10\%), divorciado/a (5\%), outro (1\%). A maioria (77\%) dos/as participantes eram naturais do Rio Grande do Sul, seguidos de 5\% do Paraná, 5\% São Paulo e o restante distribuídos nos outros estados do Brasil. Dos/as participantes da pesquisa $15,87 \%$ possuíam naturalidade diferente do atual estado de moradia.

Apenas um participante possuía ensino fundamental incompleto, 34\% possuíam pósgraduação stricto sensu (completa ou incompleta), 20,93\% possuíam pós-graduação lato sensu (completa ou incompleta), 57\% ensino superior (completo ou incompleto) e 6,01\% curso técnico (completo ou incompleto) ou ensino médio. Em relação à área de formação superior, 27,90\% dos/as participantes se concentravam na área de humanas, 3\% na área de ciências biológicas, 19,56\% na área de saúde, 7,25\% na área de exatas, 7,25\% na área de ciências sociais e 6,86\% responderam a opção "outro".

O rendimento financeiro individual teve maior concentração na faixa de ganhos entre $\mathrm{R} \$ 1.000,00$ e $\mathrm{R} \$ 2.000,00$ com 20,10\%, seguido pela faixa de ganhos abaixo de $\mathrm{R} \$ 500,00$ para $18,87 \%$. Já o rendimento familiar segue em ordem crescente conforme as faixas de ganho, tendo maior concentração na faixa acima de R \$ 5.000,00 com 47,88\%.

Grande parte dos participantes relatou não ter filhos (73\%). Dentre aqueles que possuíam filhos, a maior parte possuía um (23\%) ou dois (12\%). Em relação a religião ou crença religiosa, grande parte $(68 \%)$ respondeu ter alguma crença ou religião. 


\section{Instrumentos}

Foi elaborado um questionário sociodemográfico e duas vinhetas as quais foram respondidas pela internet, por meio da ferramenta Formulários Google. O questionário sociodemográfico foi construído especificamente para este estudo e teve como objetivo investigar questões sobre gênero, idade, escolaridade, formação, região em que mora, etc.

Os/as participantes, além de responderem a um questionário sociodemográfico, responderam duas vinhetas construídas com base na literatura feminista e com a experiência em pesquisa na área pelas/os pesquisadoras/es, a fim de trazer característica cotidianas às mesmas. A construção do instrumento decorreu do fato de não haver, na literatura nacional, um instrumento específico, em questionário fechado ou semiaberto, para investigar representações sociais acerca dos feminismos.

A Vinheta Um foi: "Imagine uma mulher solteira, com dois filhos, negra e que vive em uma comunidade de baixa renda. Feminista, luta a favor dos direitos das mulheres. Como você descreveria esta mulher? Descreva, pelo menos, três características". A Vinheta Dois foi: "Imagine uma estudante universitária, branca e com boas condições financeiras. Solteira e sem filhos, mora com o pai e a mãe. Contra o feminismo, acredita que as mulheres têm direitos iguais aos dos homens na contemporaneidade. Como você descreveria esta mulher? Escreva, pelo menos, três características".

Embora as vinhetas tenham foco no feminismo, optou-se por construí-las em relação a outros marcadores sociais de diferença, tais como raça/etnia e classe social. Sabe-se que o preconceito parte de uma lógica interseccional (Crenshaw, 1991), a qual envolve uma superposição ou entrelaçamento de atitudes negativas frente a características consideradas inferiores.

\section{Procedimentos}

O projeto de pesquisa foi submetido e aprovado pelo Comitê de Ética (CEP) da IMED, sob parecer n. 90354518.2.0000.5319. O link do formulário online foi enviado para vários emails, grupos de whatsapp, facebook, twitter e Instagram com o intuito de abarcar o maior número possível de respondentes de vários estados, idades, perfis sociais e econômicos. Foi solicitado que todas/os as/os adultas/os que recebessem o link do formulário da pesquisa pudessem compartilhar com o maior número de pessoas possível. Como o intuito da pesquisa era investigar as representações sociais dos feminismos em brasileiros/as e variáveis 
associadas, não houver critérios específicos de inclusão/exclusão a não ser a idade mínima de 18 anos e ter acesso à internet para responder a pesquisa. A grande variação da idade, de perfis socioeconômicos e culturais era um dos objetivos, com o intuito de abarcar as percepções do senso comum e se elas são compartilhadas independentemente de diferenças de perfis.

Após concordar com os objetivos da pesquisa e instrumentos a serem respondidos, por meio do Termo de Consentimento Livre e Esclarecido (TCLE), cada participante respondeu à pesquisa online e teve acesso à segunda via do TCLE por meio de um link em formato PDF. O link para responder ao questionário permaneceu na internet durante dois meses e meio (de julho a setembro de 2018).

\section{Análise dos dados}

A análise das respostas (características/palavras) das vinhetas seguiu os seguintes procedimentos: foram solicitadas para cada vinheta a descrição mínima de três e máximo de cinco palavras características. Com o intuito de homogeneizar o número de palavras/características, foram utilizadas as três primeiras, já que nas instruções das respostas das características as/os participantes deveriam descrever, pelo menos, três características, as quais eram obrigatórias para ser avançar na página de respostas do link da pesquisa. Além disso, ao analisar as respostas, percebeu-se que a maior parte das/os adultas/os descreveu apenas três e não cinco características.

Posterior à união das palavras/características semelhantes, foi realizada, por duas pesquisadoras independentes, a categorização em grupos e atribuídos valores para palavras consideradas neutras (0), negativas (1) e positivas (2). Isso foi feito com base nas representações de valência positiva e valência negativas das palavras em pesquisas sobre gênero, feminismos e representações sociais e pelas experiências prévias das pesquisadoras como supervisoras de estágio (clínico, escolar e sociais comunitários). Por exemplo, no senso comum, é percebido como positivo uma mulher ser mãe, pois é um conceito culturalmente naturalizado. Já uma mulher solteira é, ainda, percebida como uma pessoa que precisa de auxílio ou que está infeliz por não ser mãe.

As duas categorizações independentes foram agrupadas e, em caso de discordâncias, foi consultado um terceiro pesquisador (juiz). Após, as palavras foram organizadas em grandes categorias de acordo com o seu sentido semântico, categorizadas da seguinte maneira: 
Características Pessoais: são palavras que expressam valores formadores de caráter e características próprias relacionadas a subjetividade como: corajosa (2), competente (2), autocrítica (2), batalhadora (2), decidida (2), dedicada (2), esperançosa (2), de fibra (2), garra (2), guerreira (2), bitolada (1), tonga a1 (1), ignorante (1), lutadora (2). Características Sociais: descrevem situações sociais, do meio de convivência e relacional como: ativista (2), dureza (1), discriminada (1), empoderada (2), esquerda (0), exemplo (2), vulnerável (2), mãe (2), minoria (1), periférica (0), racismo (1), irmã (0), filha (0)

Características Emocionais: expressam os fatores relacionados ao emocional e sentimentos descritos pelos/as participantes: baixa autoestima (1), humana (2), carente (1), autossuficiente (2), altruísta (2), empática (2), orgulhosa (2), feliz (2), afetiva (2) e ambiciosa (2).

Características Físicas: descrições de fatores físicos e estéticos relacionados às mulheres descritas nas vinhetas, tais como: cabelo crespo (0), cabelo afro (0), mulher $(0)$, cansada (1), negra (0), branca (0), sexo feminino (0), cheirosa (2), bonita (2), loira $(0)$, morena $(0)$.

Para verificar diferenças nas características empregadas para cada vinheta de acordo com características sociodemográficas dos/as participantes, foram realizados os testes $U$ de Mann-Whitney e $H$ de Kruskal-Wallis. Ainda, estatística descritiva (média, desvios-padrão e frequência) foi realizada com o intuito de descrever o perfil dos/as participantes.

\section{Resultados e Discussão}

A média geral nos atributos para a Vinheta Um (mãe, feminista e mulher negra) foi de 3,45 $(D P=1,31)$, menor do que a da Vinheta Dois (universitária, mulher branca e antifeminista) $(M=5,32 ; D P=1,18)$. Estes dados revelam que os/as participantes do estudo, no geral, atribuíram à mulher branca antifeminista características mais positivas do que para a mulher negra, mãe e feminista. As características negativas relacionadas à Vinheta Um podem refletir como o olhar direcionado para a mulher negra está vinculado a representações sociais que acusam um racismo articulado entre as estruturas sociais, que ultrapassam questões de gênero, etnia e classe social (Brah, 2006). Embora o intuito fosse explorar as representações sociais acerca dos feminismos, entende-se que o fato da mulher da Vinheta Um ser negra 
possa contribuir para que as representações sociais sejam negativas, de acordo com a categorização proposta no presente manuscrito.

De fato, ser mulher e ser negra produz uma dupla subvalorização, tal como demonstra o presente estudo em que a representação social da mulher negra é mais negativa que a da mulher branca. O feminismo negro busca, em sua militância, o combate ao racismo sofrido pelas mulheres negras, que acabam sofrendo uma sobreposição de discriminações que envolvem gênero e raça/etnia. Além das lutas contra a discriminação também ocorre a luta pelo rompimento de padrões de beleza europeus, aceitação da estética negra e a aceitação de suas origens (Brah, 2006; Carneiro, 2003; Oliveira, 2016; Rios \& Silva, 2015).

A ocorrência de mais características negativas atribuídas à Vinheta Um pode ser resultado não apenas das representações sobre o feminismo ou da raça negra, mas uma representação social da condição socioeconômica da universitária da Vinheta Dois que, por ser branca, tem privilégios quando comparada com a negra. Para a Vinheta Um são expressos estereótipos, preconceitos e expectativas ruins à família dessas mulheres, sendo assim, as respostas diante dessa vinheta podem expressar tais representações (Santos, 2017).

O teste $U$ de Mann-Whitney foi realizado com o intuito de comparar se haviam diferenças estatisticamente significativas, por faixas etárias, na atribuição valorativa quanto às características da Vinheta Um com a Vinheta Dois. Os grupos etários foram divididos pela mediana ( $M d=27)$, sendo os/as mais novos/as do grupo 1 (de 18 a 27 anos) e mais velhos, do grupo 2 (de 28 a 79 anos). Os resultados indicaram haver diferenças estatisticamente significativas $(p=0,04)$ apenas na Vinheta Dois, tendo os/as participantes mais velhos/as (de 28 a 79 anos) atribuído mais características positivas à mulher branca.

As divergências entre as diferentes faixas etárias podem apontar como a formação da representação social deriva do contexto cultural de cada geração (Guareschi \& Jovchelovitch, 2002), o que foi manifestado na diferença entre as atribuições de características nas vinhetas. Os fenômenos sociais vividos pelos/as participantes mais velhos/as da pesquisa representavam o feminismo como algo hostil à moralidade e ao equilíbrio social. No entanto, com o passar dos anos, houve a dissociação do feminismo, por parte da maioria das mulheres que não encontrava sentido na luta feminista, mesmo identificando as conquistas feministas no seu cotidiano e usufruindo dos direitos conquistados. A visão da mulher da Vinheta Dois ilustra algo semelhante, ao apresentar uma mulher a favor dos direitos iguais entre os diferentes gêneros, porém, com uma posição antifeminista, podendo então ter ocorrido uma identificação ao perfil juntamente com a aceitabilidade social (Gonçalves \& Pinto, 2011; Pinto, 2010). Ao contrário dos/as participantes mais velhos/as, os demais possuem uma 
maneira diferente de se relacionar e ter uma formação política e social. Como Diniz e Silva (2017) demonstram, cada vez mais vinculada ao meio digital, a propagação de informações é mais dinâmica e o acesso é mais rápido. Martinez (2017) aponta que assuntos como o feminismo são pautados e discutidos gerando conhecimento sobre o movimento.

Um estudo sobre o movimento feminista no Brasil, relata que as mulheres feministas não eram vistas de maneira positiva pela sociedade no início do movimento no país (Pinto, 2010). Os resultados da presente pesquisa indicam que os participantes com mais idade deferiram características mais positivas à mulher da Vinheta Dois que possuía um posicionamento aversivo ao feminismo, embora esse resultado deve ser analisado com cautela, visto que o grupo possui grande variabilidade no que diz respeito à idade (28 a 79 anos) e, além disso, a pesquisa foi realizada online, o que implica que grande parcela de adultas/os não tenha tido a possibilidade de respondê-la.

Embora os resultados quanto às diferenças nas características atribuídas às vinhetas dentre as gerações não possam ser generalizados, destaca-se que os adultos, mesmo de gerações diferentes, possuem o mesmo posicionamento que idosos. Este aspecto pode referirse não apenas à idade, mas à forma como se recebe a educação, transmitida, muitas vezes, de geração para geração. Ainda, parece haver transgeracionalidade das representações sociais gradativamente desconstruídas pela geração mais nova. Isso quer dizer que as representações sociais são ideias, crenças e pensamentos compartilhados entre grupos sociais, culturais e até mesmo geracionais que se tornam naturalizados. A naturalização faz parte do processo de objetivação, pois acaba por dessensibilizar ou "esquecer" os processos de ancoragem originalmente presentes na construção de uma representação social, o que facilita a sensação de materialidade de uma representação (Moscovici, 2007).

Apesar de algumas representações sociais manterem-se presentes da mesma forma por muitas gerações, as redes sociais vêm contribuindo para realizar mudanças de pensamento e isso tem ocorrido em relação ao que é feminismo, visto que o movimento feminista que teve maiores benefícios com esta plataforma nova de comunicação foi o feminismo negro. No entanto, mesmo que as pessoas de mais idade utilizem as redes sociais, parece que algumas crenças sobre gênero e raça continuam a se propagar (Oliveira, 2016).

A internet teve como contribuição o espaço para divulgação e disseminação do movimento feminista, do digital para as ruas, dando início ao despertar do movimento feminista militante no Brasil (Brito, 2017). Essas disseminações de informações nas redes sociais podem ter interferido nas representações sociais. Uma vez que a presença dessas 
mídias está na rotina, da maioria, das pessoas que acabam recebendo informações sobre o feminismo, influenciando na formação da sua representação social.

No que diz respeito às diferenças quanto aos atributos em relação ao gênero, o teste $U$ de Mann-Whitney indicou haver diferença estatisticamente significativa $(p<0,001)$ apenas na Vinheta Um, tendo o gênero feminino atribuído maiores características positivas para a mulher do que os participantes do gênero masculino. A identificação pelas lutas feministas pode ser o motivo pelo qual as mulheres atribuem características mais positivas para a Vinheta Um do que os homens. A representação social do feminismo no Brasil vem sendo alterada e grande parte disso acontece pela relação com que as pessoas têm com as plataformas digitais. As representações sociais podem ser construídas por meio de conteúdos divulgados na internet, como Oliveira (2016) refere sobre o feminismo negro, Martinez (2017) a respeito da divulgação por meio do Facebook e Lapa, Coelho, Ramos e Malini (2015) sobre o empoderamento nas redes sociais.

O teste de $H$ de Kruskal-Wallis foi realizado com o intuito de verificar se havia diferenças, por renda familiar mensal, nas características atribuídas às duas mulheres das vinhetas. Os grupos foram divididos em três considerando-se as frequências em cada categoria (grupo 1- renda menor que 500 a 2 mil reais; grupo 2 - de 2 mil a 5 mil reais e grupo 3 - maior que 5 mil reais). Não houve diferenças estatisticamente significativas, quanto à renda, na atribuição de características em nenhuma das vinhetas. Esse aspecto pode indicar que o nível socioeconômico não influencia na percepção sobre o feminismo, ao menos nesta amostra.

O mesmo teste foi realizado para comparar atributos em relação às áreas de atuação profissional, considerando-se cinco áreas (humanas, biológicas, sociais, da saúde e exatas). Os resultados indicaram não haver diferenças estatisticamente significativas nas características atribuídas na Vinheta Um, nem na Vinheta Dois, por área de atuação profissional. Esse resultado destoa do esperado, na medida em que a hipótese era de que as ciências humanas e sociais pudessem apresentar características mais positivas à Vinheta Um (mãe, feminista e mulher negra) em contraposição às outras áreas, pois o tema em questão é mais abordado nessas áreas de conhecimento. Este resultado pode indicar especificidades no que diz respeito às pessoas que se dispuseram a responder ao questionário online, podendo indicar que aqueles que consideram o tema importante foram os que responderam. Por outro lado, não foram distribuídas de igual forma as áreas de conhecimento, sendo que a área de exatas, por exemplo, teve menos respondentes. Dessa forma, esses resultados devem ser analisados com cautela devido suas limitações quanto ao número de respondentes por grupo. 
Ainda, foram comparadas as características atribuídas por nível de escolaridade, considerando-se três grupos (grupo 1- ensino fundamental incompleto ao ensino médio completo; grupo 2 - ensino superior; grupo 3 - especialização lato sensu e stricto sensu). Os resultados vão de encontro às expectativas, pois esperava-se encontrar diferenças estatisticamente significativas sobre as características atribuídas às vinhetas entre pessoas com maior escolaridade, pelo fato de que o acesso à informação pode auxiliar no melhor entendimento acerca das lutas feministas. A mesma hipótese foi negada em relação ao preconceito contra diversidade sexual e de gênero no estudo de Costa, Peroni, Camargo, Pasley e Nardi (2015). No estudo, os pesquisadores esperavam encontrar uma correlação negativa entre preconceito e o tempo passado pelo indivíduo dentro de uma das maiores universidades do país. Assim como no presente estudo não houve diferença significativa, no estudo de Costa et al. (2015) não houve correlação significativa.

Pode-se considerar a perspectiva de que com a internet, o conhecimento e informação mudam sua posição vertical, de acesso a quem teria mais escolaridade e condições econômicas, para uma linha horizontal na qual todos têm acesso a diversas plataformas que podem informar e educar sobre os mais diversos assuntos. Com isso, a manifestação de opiniões e a forma como os conteúdos são apresentados nas mídias sociais contribuem para um novo meio de formação cidadã, apresentando e educando as pessoas, desmistificando e ratificando representações errôneas sobre o feminismo (Lapa et al., 2015; Martinez, 2017). No entanto, mesmo que haja na internet discussão e propagação do feminismo, de forma geral, alguns padrões que ferem a luta de representatividade e aceitação da autoimagem são reproduzidos. Isso acontece, por exemplo, no cinema, na narrativa em que mulher negra possui um posicionamento inferior à mulher branca. Analisando os resultados do presente estudo, pode-se inferir que a democratização da informação pode contribuir para a construção das representações sociais de forma mais homogênea. Portanto, não houve diferença nas características atribuídas às mulheres das vinhetas entre os grupos de diferentes escolaridades.

Teste $U$ de Mann-Whitney foi realizado com o intuito de verificar se havia diferenças nas características atribuídas para as mulheres das vinhetas nos/as participantes que possuíam filhos ou não. Pais/mães atribuíram características mais positivas $(p=0,05)$ para a mulher da Vinheta Dois (universitária, mulher branca e antifeminista) do que participantes sem filhos. Não houve diferença estatisticamente significativa na Vinheta Um.

A transmissão e interação entre gerações sobre a discussão do real significado do feminismo é apontada no estudo de Gonçalves e Pinto (2011). Esses autores discutem estudos que apontam que houve uma lacuna geracional, na qual as mulheres perderam, na sua maioria, 
o significado desse movimento. Aquelas que permaneceram ligadas às causas e estudo sobre o feminismo foram mulheres que conviviam em meios acadêmicos e frequentavam ambientes propícios a esta discussão. Este fenômeno social relacionado ao feminismo, causou um rompimento na união das mulheres na luta feminista. Porém, a geração mais nova ressignificou a imagem feminista apresentada pela geração anterior, com acontecimentos atuais como a Primavera Feminista (Brito, 2017). Esse evento pautou o feminismo para a geração atual, gerando novos debates e fomentação da discussão sobre o que é feminismo, como também a razão de sua existência.

Analisando os resultados deste estudo, dentre os pais e as mães que atribuem as características positivas à Vinheta Dois, 86,9\% deles possuía 31 anos ou mais. São os pertencentes a geração que não conseguiu ter um vínculo empático e/ou positivo com o feminismo. Já os participantes do outro grupo, sem filhos, pertencem à geração mais nova, com vínculos positivos ao movimento feminista, considerando que 77,9\% tinham faixa etária menor que 30 anos.

O mesmo teste foi realizado para verificar diferenças nas características atribuídas por participantes que possuem ou não religião. Os resultados indicaram que, em caso positivo, foram atribuídas características mais positivas na Vinheta Dois (universitária, mulher branca e antifeminista), em comparação aos que não possuem religião. Não houve diferença estatisticamente significativa na Vinheta Um. A complexidade envolta no que diz respeito ao feminismo e religião podem influenciar a maneira como pessoas religiosas expressam sua representação social do movimento, que surge a partir do conhecimento que possuímos e ao qual adaptamos novas informações também por meio dele (Moscovici, 2007). Nunes (2017) refere a religião como um ponto a ser discutido para a saúde, valorização e liberdade da mulher, observando que as religiões de origem europeia possuem uma visão repressiva da mulher, principalmente sendo negra. Dessa forma, o aprendizado por meio da religião pode ter consequências sobre as características atribuídas a Vinheta Dois (universitária, mulher branca e antifeminista). A religiosidade está sendo discutida atualmente, no intuito de promoção de qualidade de vida, como algumas questões religiosas podem prejudicar no atendimento de saúde (Nunes, 2017) e atendimento social (Pinheiro, 2015).

\section{Considerações Finais}

O objetivo deste estudo foi investigar as representações sociais dos feminismos em brasileiros/as e variáveis associadas. Os/as participantes do estudo, no geral, atribuíram à 
mulher branca, antifeminista e universitária (Vinheta Dois) características mais positivas do que para a mulher negra, mãe e feminista (Vinheta Um). Quando comparados por gênero, as mulheres atribuíram características mais positivas, do que os homens, para a Vinheta Um.

Por grupo etário, houve diferenças estatisticamente significativas. Participantes mais velhos/as (de 28 anos a 79 anos) atribuíram características mais positivas para a Vinheta Dois do que os outros grupos etários. A divisão dos grupos etários foi realizada por meio da mediana e, ainda assim, considera-se que há grande dispersão, sendo grande a variação de idade no grupo, devendo-se ter cautela ao generalizar tais resultados. Todavia, os/as adultos/as mais jovens assemelham-se aos/às mais velhos/as no que diz respeito às características que atribuem para a mulher da Vinheta Dois.

Ainda no que diz respeito às diferenças por grupos, participantes que possuíam alguma religião atribuíram mais características positivas à mulher da Vinheta Dois. Quando comparadas as atribuições de características por participantes que possuíam ou não filhos, os primeiros atribuíram mais características positivas para a mulher da Vinheta Dois. No entanto, esse resultado deve ser discutido, pois caberia uma análise estatística comparando-se às atribuições de acordo com as características (pessoal, social, emocional e física) negativas e positivas para cada vinheta, que poderiam se referir a condição social e racial, que não foco do presente estudo, mas que pode ter interferido no resultado.

Não houve diferenças estatisticamente significativas quanto à renda e área de atuação na atribuição de características em nenhuma das vinhetas. Embora fosse esperado que as ciências humanas e sociais, por exemplo, pudessem apresentar características mais positivas à Vinheta Um em contraposição às outras áreas. Ainda, os resultados sobre a hipótese de haver diferenças estatisticamente significativas sobre as características atribuídas às vinhetas entre pessoas com maior escolaridade, pelo fato de que o acesso às informações que podem auxiliar no melhor entendimento acerca das lutas feministas não confirmou essa hipótese.

De maneira geral, os resultados desta pesquisa demonstram a necessidade de esclarecimentos sobre os feminismos e liberdade da mulher, além das diferentes características acerca das mulheres, classes sociais, cor etc. Nessa pesquisa observou-se nas respostas empregadas à Vinheta Dois, ao questionar os/as participantes sobre a visão da mulher feminista, que foram atribuídas características mais positivas àquela em que a mulher não se assumia como feminista, o que indica a relação negativa que se tem com os feminismos, mesmo que sem o rótulo "feminista" muitas pessoas sejam coniventes com os objetivos do movimento. 
A propaganda negativa em torno dos feminismos se agrava quando representantes políticos reproduzem declarações equivocadas e pejorativas com o objetivo de desencorajar aproximações com o movimento. A escolha dos termos utilizados como ofensas às feministas resume mulheres a noções de feiura, uma das pautas mais importantes do feminismo, que busca libertar mulheres de padrões de beleza e objetificação de seus corpos. Recentemente, esses representantes têm declarado efusivamente a necessidade da adequação aos "papéis de gênero", em um modelo ultrapassado de hierarquia de legitimidades.

Além disso, pode-se investigar e discutir estudos relacionados a essa temática para perceber como se desenvolve a percepção popular, no Brasil, sobre a militância do movimento feminista e sua repercussão no cotidiano feminino. De fato, sabe-se que as representações podem influenciar em situações vivenciadas por mulheres que são julgadas por estes preconceitos, seja por serem feministas, ou ser de determinada etnia, fazendo com que haja a necessidade de maior crítica acerca dessas representações sociais.

No geral, ao analisar o estudo, pode-se apontar como limitações o instrumento utilizado (vinhetas), pois estas foram construídas para o estudo e são de autorrelato, o que pode facilitar que as pessoas tenham respondido de acordo com a desejabilidade social, mesmo que o estudo tenha sido online e anônimo. Para tanto, sugere-se a construção ou adaptação de um instrumento que possua boas propriedades psicométricas adequadas para utilização em pesquisas nacionais.

Outra limitação refere-se ao gênero dos respondentes do estudo, sendo que 78\% das/os adultos foram mulheres, o que pode ter influenciado nos resultados. Ainda, sugere-se a inserção de outras variáveis no estudo como a etnia ou cor, educação recebida, que podem influenciar nas representações sobre o feminismo, além de uma maior diversidade de respondentes, com amostra aleatória.

\section{Referências}

Alves-Mazzotti, A. J. (1994). Representações sociais: Aspectos teóricos e aplicações à educação. Em Aberto, 14(61). doi: 10.15603/1982-8993/ml.v1n1p18-43

Arruda, A. (2002). Teoria das representações sociais e teorias de gênero. Cadernos de Pesquisa, (117), 127-147. doi: 10.1590/S0100-15742002000300007

Beauvoir, S. (1967). O segundo sexo (2a ed.). São Paulo, SP: Difusão Europeia do Livro. 
Böhmer, M. F. (1993). Feminismo radical y feminismo liberal: Pasos previos para una discusión posible. Doxa. Cuadernos de Filosofía del Derecho, (13), 179-190. doi: 10.14198/doxa1993.13.09

Brah, A. (2006). Diferença, diversidade, diferenciação. Cadernos Pagu, (26), 329-376. doi: $10.1590 / \mathrm{s} 0104-83332006000100014$

Brito, P. C. DE S. (2017, Agosto). Primavera feminista: A internet e as manifestações de mulheres em 2015. Seminário Internacional Fazendo Gênero 11 \& 13th Women's Worlds Congress. Universidade Federal de Santa Catarina, Florianópolis, SC, Brasil. Recuperado de http://www.wwc2017.eventos.dype.com.br/site/anaiscomplementares.

Butler, J. (1990). Gender trouble: Feminism and the subversion of identity. New York, NY: Routledge.

Carneiro, S. (2003). Mulheres em movimento. Estudos Avançados, 17(49), 117-133. doi: 10.1590/S0103-40142003000300008

Colling, A. M. (2017). As mulheres e a ditadura militar no Brasil. História em Revista, 10, 1 10. doi: 10.15210/HR.V10I10.11605.G7457

Costa, A. B., Peroni, R. O., De Camargo, E. S., Pasley, A., \& Nardi, H. C. (2015). Prejudice toward gender and sexual diversity in a Brazilian public university: Prevalence, awareness, and the effects of education. Sexuality Research and Social Policy, 12(4), 261-272. doi: 10.1007/s13178-015-0191-z

Crenshaw, K. W. (1991). Mapping the margins: Intersectionality, identity politics, and violence against women of color. Stanford Law Review, 43(6), 1241-1299. doi: $10.2307 / 1229039$

Diniz, J. M. A., \& Silva, M. E. (2017). Meu perfil de Facebook me representa! Um estudo da relação entre feminismo e o eu estendido digital. Revista Alcance, 24(3), 309-328. doi: 10.14210/alcance.v24n3(jul/set).p309-328

Diorio, A. P. I., Costa, M. A. F., \& Santana, G. C. A. (2017). A teoria das representações sociais como referencial teórico-metodológico na pesquisa em ensino de biociências e saúde. Revista Práxis, 9(17), 23-32. Recuperado de http://revistas.unifoa.edu.br/index.php/praxis/article/view/685

Esmeraldo, G. G. S. L. (2006). O feminismo no plural: para pensar a diversidade constitutiva das mulheres. Revista Estudos Feministas, 14(3), 829-831. doi: 10.1590/s0104026x2006000300018 
Gonçalves, E., \& Pinto, J. P. (2011). Reflexões e problemas da "transmissão" intergeracional no feminismo brasileiro. Cadernos Pagu, (36), 25-46. doi: 10.1590/s010483332011000100003

González Rey, F. (2008). Subjetividad social, sujeto y representaciones sociales. Diversitas, 4(2), 225-243. doi: 10.15332/s1794-9998.2008.0002.01

Guareschi, P. O., \& Jovchelovitch, S. O. (2002). Textos em representações sociais (7a ed.). Rio de Janeiro: Vozes.

Hartmann, S. M. (2017). Liberal feminism and the reshaping of the new deal order. Champaign, IL: University of Illinois Press. doi: 10.5406/illinois/9780252036866.003.0010

Jesus, J. G. (Ed.). (2014). Transfeminismo: Teorias e práticas. Rio de Janeiro, RJ: Metanoia.

Lapa, A. B., Coelho, I. C., Ramos, V. C., \& Malini, F. (2015). Fatores e circunstâncias para o empoderamento do sujeito nas redes sociais atas congresso ibero-americano em investigação qualitativa. Atas CIAIQ 2015, Investigação Qualitativa em Educação, 2, 594-600. Recuperado de https://proceedings.ciaiq.org/index.php/ciaiq2015/article/view/331

Louro, G. L. (Ed.). (1999). O corpo educado: Pedagogias da sexualidade. Belo Horizonte, MG: Autêntica.

Martinez, F. J. (2017, Agosto). O conhecimento feminista na era digital: Grupos de discussão do facebook como uma nova epistemologia do conhecimento. Seminário Internacional Fazendo Gênero 11 \& 13th Women's Worlds Congress. Universidade Federal de Santa Catarina, Florianópolis, SC, Brasil. Recuperado de http://www.wwc2017.eventos.dype.com.br/site/anaiscomplementares

Meyer, D. E. (2004). Teorias e políticas de gênero: Fragmentos históricos e desafios atuais. Revista Brasileira de Enfermagem, 57(1), 13-18. doi: 10.1590/s003471672004000100003

Moscovici, S. (2007). Representações sociais: Investigações em psicologia social (5a ed). Petrópolis, RJ. Vozes.

Nunes, M. J. F. R. (2017). Feminismo, gênero e religião: Os desafios de um encontro possível. Estudos de Religião, 31(2), 65-76. Recuperado de https://dialnet.unirioja.es/servlet/articulo?codigo=6342669

Oliveira, L. T. B. (2016, Abril). Narrativas em rede: Feminismo negro nas redes sociais. Anais do Seminário Nacional de Sociologia da UFS. Universidade Federal de Sergipe, 
Aracaju,

SE,

Brasil.

Recuperado

de

https://seer.ufs.br/index.php/snsufs/article/download/6080/5093

Pinheiro, P. W. M. (2015). Serviço social, neoconservadorismo religioso e o desafio para a formação profissional. Temporalis, 15(29), 195-220. Recuperado de http://portaldepublicacoes.ufes.br/temporalis/article/view/925um

Pinto, C. R. J. (2010). Feminismo, história e poder. Revista de Sociologia e Política, 18(36), 15-23. doi: 10.1590/S0104-44782010000200003

Prehn, D. R., \& Hüning, S. M. (2017). O movimento feminista e a psicologia. Psicologia Argumento, 23(42), 65-71. doi: 10.7213/rpa.v23i42.20101

Rich, A. (1980). Compulsory heterosexuality and lesbian existence. Signs: Journal of Women in Culture and Society, 5(4), 631-660. doi: 10.1086/493756

Rios, R. R., \& Silva, R. DA. (2015). Discriminação múltipla e discriminação interseccional: Aportes do feminismo negro e do direito da antidiscriminação. Revista Brasileira de Ciência Política, (16) 11-37. doi: 10.1590/0103-335220151602

Santos, K. C. D. M. (2017). Análise da representação da mãe solteira nos meios de comunicação e na sociedade por meio do grupo focal. Anais do EVINCI-UniBrasil, Cadernos de artigos científicos, 3(2), 669-686. Recuperado de https://portaldeperiodicos.unibrasil.com.br/index.php/anaisevinci/issue/view/105

Scott, J. W. (1986). Gender: A useful category of historical analysis. The American Historical Review, 91(5), 1053-1075. doi: 10.2307/1864376

Simien, E. M. (2004). Black feminist theory. Women \& Politics, 26(2), 81-93. doi: 10.1300/j014v26n02_04

Snyder, R. C. (2008). What is third $\square$ wave feminism? A new directions essay. Signs: Journal of Women in Culture and Society, 34(1), 175-196. doi: 10.1086/588436

Swirsky, J. M., \& Angelone, D. J. (2014). Femi-nazis and bra burning crazies: A qualitative evaluation of contemporary beliefs about feminism. Current Psychology, 33(3), 229245. doi: 10.1007/s12144-014-9208-7

Tong, R. (2018). Marxist and socialist feminism. In R. Tong \& T. F. Botts, Feminist Thought (pp. 93-125). New York: Routledge. doi: 10.4324/9780429493836-4 


\section{Endereço para correspondência}

\section{Naiana Dapieve Patias}

Universidade Federal de Santa Maria - UFSM

Prédio 74 B, sala 3209, Santa Maria - RS, Brasil. CEP 97105-900

Endereço eletrônico: naipatias@hotmail.com

\section{Tayná da Silva Ferreira}

Rua Teixeira Soares, 839, Edifício João Zanatta Filho, 204, $2^{\circ}$ Andar, Passo Fundo - RS, Brasil. CEP 99010-080

Endereço eletrônico: tayna.sfer@gmail.com

\section{Icaro Bonamigo Gaspodini}

\section{UNISINOS}

Avenida Unisinos, 950, Cristo Rei, São Leopoldo - RS, Brasil. CEP 93022-750

Endereço eletrônico: icaroicaro@gmail.com

\section{Paula Andréa Prata-Ferreira}

Universidade Estácio de Sá

Estrada do Galeão, 1900, Jardim Carioca, Rio de Janeiro - RJ, Brasil. CEP 21931-420

Endereço eletrônico: paulaprata@gmail.com

\section{Clarissa Pinto Pizarro de Freitas}

Pontifícia Universidade Católica do Rio de Janeiro - PUC-Rio

Rua Marquês de São Vicente, 225, Gávea, Rio de Janeiro - RJ, Brasil. CEP 22451-900

Endereço eletrônico: freitas.cpp@gmail.com

Recebido em: 28/10/2019

Reformulado em: 27/05/2020

Aceito em: 31/05/2020

\section{Notas}

* Doutora em Psicologia (UFRGS).

** Psicóloga (IMED).

*** Doutorando em Psicologia na UNISINOS.

**** Doutora em Psicologia pela Universidade Salgado de Oliveira (UNIVERSO).

***** Doutora em Psicologia pela Universidade Federal do Rio Grande do Sul (UFRGS/2016).

${ }^{1}$ Gíria equivalente à boba, palerma, idiota.

Este artigo de revista Estudos e Pesquisas em Psicologia é licenciado sob uma Licença Creative Commons Atribuição-Não Comercial 3.0 Não Adaptada. 